стремится к прямо противоположному. И вот здесь проявляется момент рождающегося субъекта: он рождает, и поэтому растет! Собственно, этот момент порождения и принимается нами в качестве смысла жизни, и этот смысл вложен в диагностику всех ресурсов.

Психологу предстоит правильно выбрать метод и язык общения: как беседовать, начинать с клиентом работать, как создать ему такую атмосферу, чтобы он проявил свой жизненный потенциал. Важно понимать, что все ресурсы по отношению друг к другу находятся в паритете. Только у субъекта есть предпочтение проявить тот или иной ресурс в данной жизненной ситуации. Но вместе с тем, у субъекта как целостного существа, может быть стратегический, судьбинный, ведущий ресурс, актуализация которого в ходе встреч с психологом, поможет ему гармонизировать себя и по другим ресурсам.

\title{
Литература
}

1. Тесля С.Н. Личностный ресурс учителя как критерий его социальной идентичности / Университетское образование современного педагога: Сборник научных статей Всероссийской научно-практической конференции 13 октября 2016 года /Под ред. И.В. Гладкой, С.А. Писаревой. СПб: Изд-во РГПУ им. А.И. Герцена, 2016. - С. 395-401.

2. Исаченко А.Ю., Тесля С.Н.. Шашков А.В. Психологическое консультирование: экзистенциально-гуманистическое консультирование: учебное пособие. - Сочи: РИЦ ФГБОУ ВПО «СГУ», 2015. - С.42-48.

3. Тесля С.Н. Понятия «субъектный подход», «субъектность» и «человек как субъект жизни» / Материалы Международной науч. конф. Человек, Субъект. Личность в современной психологии Посв.80 - летию А.В.Брушлинского, 10-11окт. 2013года, Москва. Отв.ред. А.Л. Журавлев, Е.А.Сергиенко. - М.: Издательство «Институт Психологии РАН», 2013.Т.1. C.355-358.

\section{СПЕЦИФИКА СУБЪЕКТИВНОЙ КАРТИНЫ ЖИЗНЕННОГО ПУТИ У ЖЕНЩИН С РАЗЛИЧНЫМ УРОВНЕМ УДОВЛЕТВОРЕННОСТИ БРАКОМ}

Макаревская И.Г.

Проблема жизненных перспектив личности, субъективной картины жизненного пути становится все более актуальной в современной психологии. Возрастание темпов жизни требует от человека более осмысленного отношения к времени собственной жизни, так как умение предвидеть, прогнозировать и строить жизненные планы влияют на жизненный выбор, организацию и осуществление деятельности. Жизненный путь является тем целостным специфическим процессом, в котором происходит функционирование, изменение и развитие личности.

Проблемой жизненного пути занимались отечественные и зарубежные исследователи: К.А.Абульханова-Славская, Б.Г.Ананьев, Л.И.Анцыферова, 
Р.А.Ахмеров, А.В.Брушлинский, Ш.Бюлер, У.Денис, Н.А.Логинова, Н.А.Рыбников, С.Л. Рубинштейн и др.

К настоящему моменту область представлений человека о времени жизни изучена достаточно широко. Исходя из научного взгляда на личность как субъекта жизни, выступающего в роли организатора собственного жизненного пути (Б.Г. Ананьев, К.А. Абульханова-Славская, С.Л.Выготский) складывается научная традиция понимания субъективной картины жизни как важнейшей характеристики самосознания личности, которая развернута во времени, отражает этапы индивидуального и социального развития человека, состоит из жизненных событий и учитывает динамику их реализации (В.Г.Асеев, Я.В.Васильев, Е.И.Головаха, В.И.Ковалев, А.А.Кроник, С.Л.Марков, Н.Н.Толстых, Р.Кастенбаум, Т.Коттле, Ж.Нюттен и др.).

Несмотря на достаточно большое количество работ, посвященных изучению жизненного пути личности, мало исследованной остается проблема связи субъективной картины жизненного пути личности с удовлетворенностью в разных сферах социального взаимодействия: профессиональной, досуговой, семейной.

В ходе развития личности, по мере того как человек приобретает жизненный опыт, перед ним не только открываются все новые стороны бытия, но и происходит более или менее глубокое переосмысливание жизни. Этот процесс ее переосмысливания, проходящий через всю жизнь человека, образует основное содержание его существа, определяет мотивы его действий и внутренний смысл тех задач, которые он разрешает в жизни. Именно поэтому изучение психологии жизненного пути правомерно рассматривать в контексте различенных сфер жизни, и, в, частности, как в нашей работе, в контексте удовлетворенности брачно-семейными отношениями.

М. Аргайл утверждал, что «семейные люди, особенно те, кто счастлив браке, ощущают более высокую степень удовлетворенности жизнью. Имеются все основания предполагать, что удовлетворенность находится в причинноследственной зависимости с супружеством» [1, с.124].

Неудовлетворенность брачно-семейными отношениями, на наш взгляд, может приводить к изменению картины будущего, переоценке событий прошлого и изменению системы ценности в настоящем, то есть способно приводить к изменениям в субъективной картине жизненного пути. Насколько справедливо подобное предположение, мы проверили в нашем эмпирическом исследовании.

В исследовании приняло участие 90 женщин различного возраста, состоящие в официально зарегистрированном браке, имеющие стаж супружества не менее 10 лет и имеющие как минимум одного ребенка. Были использованы следующие методики: тест-опросник удовлетворенности браком (В.В.Столин, Т.Л.Романова, Г.П. Бутенко); «Опросник временной перспективы» Ф. Зимбардо (в адаптации А.Сырниковой); методика определения индекса жизненной удовлетворенности; методика «Психологический возраст» Е.И. Головаха, А.А.Кроник. Полученные данные 
обрабатывались с помощью непараметрического статистического критерия UМанна-Уитни.

Наше исследование проходило в несколько этапов. На первом этапе диагностировалась степень удовлетворенности браком у женщин, принимавших участие в нашем исследовании. На основании данных, полученных на первом этапе исследования, выборка испытуемых была разделена на три группы: женщины удовлетворенные брачно-семейными отношениями - 22 человека $(24,4 \%)$; женщины, неудовлетворенных сложившимися брачно-семейными отношениями - 30 человек $(33,3 \%)$, и женщины, скорее удовлетворенные, чем неудовлетворенные браком (средний удовлетворенности браком) - 38 человек (42,2\%).

На втором этапе выявлялись особенности субъективной картины жизненного пути. В исследовании анализировались такие компоненты субъективной картины жизненного пути личности, как: временная перспектива, психологический возраст личности и общая удовлетворенность жизнью.

Для большинства испытуемых из выборки $(42,2 \%)$ оказалась наиболее характерна ориентация на «гедонистическое настоящее», для этих испытуемых во многом характерно гедонистическое, рискованное, «а мне все равно» отношение ко времени и жизни. Для таких людей типична ориентация на удовольствие, волнение, возбуждение, наслаждение в настоящем и отсутствие заботы о будущих последствиях или жертв в пользу будущих наград, такие люди живут ради сегодняшнего удовольствия.

Более, чем для трети испытуемых (для 35,5\%) субъективно наиболее значимым компонентом временной перспективы оказалось «позитивное прошлое». Временная перспектива этих респондентов характеризуется ностальгической, позитивной реконструкцией прошлого, прошлое представляется им в радужном свете.

Ориентация на будущее, поведение, которое в большей степени определяется стремлениями к целям и вознаграждениям будущего была определена для 20\% испытуемых из выборки.

Преобладание во временной перспективе таких структурных компонентов как «негативное прошлое» и «фаталистическое настоящее» было диагностировано только для 2,2\% испытуемых из выборки.

Психологический возраст по данным нашего исследования соответствует паспортному лишь для $11 \%$ испытуемых из выборки, для почти 50\% испытуемых психологический возраст превышает хронологический, еще у 40\% испытуемых он меньше хронологического.

Анализ общей удовлетворенности жизнью у испытуемых показал, что для 17 человек, что составляет 18,9 \% от числа всех испытуемых характерна высокая удовлетворенность жизнью, для 60 человек (66,7\%) - средняя удовлетворенность жизнью, для 13 человек $(14,4 \%)$ - низкая удовлетворенность прожитой частью жизни.

Для статистической обработки полученных данных, с целью выявления особенностей субъективной картины жизненного пути у женщин с разным уровнем удовлетворенности браком были избраны непараметрические 
статистические критерии U-Манна-Уитни и $\chi 2$-Пирсона. Анализ осуществлялся с использованием универсального программно-прикладного статистического пакета SPSS v.21.0.

На основании проведенного статистического анализа, выявлено, что для женщин, удовлетворенных брачно-семейными отношениями, характерна наибольшая устремленность в будущее, они соотносят цели и задачи текущей деятельности с возможными последствиями в будущем, их целеполагание не ограничивается насущным моментом, а пролонгировано по времени (при $\mathrm{p} \leq 0,001)$.

Для женщин, неудовлетворенных сложившимися брачно-семейными отношениями были определены самые низкие значения по компоненту «будущее». Таким образом, неудовлетворенные браком женщины не ориентируются на будущее, их поведение в настоящем в меньшей степени детерминируется будущими целями и задачами, чем поведение женщин с высоким или средним уровнем удовлетворенности браком.

Полученное различие по фактору «фаталистическое настоящее» между группами с высоким и средним уровнем удовлетворенности браком $(\mathrm{p} \leq 0,01)$ свидетельствует о том, что для женщин, частично неудовлетворенных браком более характерно фаталистическое и безнадежное отношение к будущему, выраженное в убеждении, что будущее предопределено, и на него невозможно повлиять собственной активностью, а настоящее следует переносить с покорностью, смирением.

Максимальные значения по показателям «гедонистическое настоящее» и «позитивное прошлое» оказались характерными в нашем исследовании для женщин со средним уровнем удовлетворенности браком. Частично удовлетворенные браком женщины, таким образом, возможно, более остальных ориентированы на получение удовольствия, на переживание волнения, возбуждения, наслаждения в настоящем, здесь и сейчас. Возможно, они более, чем женщины, полностью удовлетворенные и полностью неудовлетворенные брачно-семейными отношениями, живут в рамках сегодняшнего дня. При этом для этой же группы женщин, более характерно теплое отношение к своему прошлому, привязанность к институту семьи и семейным традициям.

Статистически значимых различий по показателям: «психологический возраст» и «удовлетворенность жизнью» между женщинами с разным уровнем удовлетворенности браком, выявлено не было.

Таким образом, выдвинутая в исследовании гипотеза подтверждена частично: существует специфика субъективной картины жизненного пути у женщин с разным уровнем удовлетворенности браком по такому компоненту как: «временная перспектива», в частности по отношению к будущему и не выявлено статистически значимых различий между группами по таким компонентам как: «психологический возраст» и «удовлетворенность жизнью».

Поставленная в нашем исследовании проблема нуждается, на наш взгляд, в дальнейшем изучении. Перспективным нам представляется проведение 
подобного анализа на выборке мужчин, анализ гендерной и этнической специфики выявленных закономерностей.

\section{Литература}

1. Аргайл М. Психология счастья. / Пер. с англ. А.Лисициной- СПб., изд-во «Питер», 2003.-272c.

2. Клюева Н.В. Влияние семейного сценария на удовлетворенность браком// Вестник Ярославского государственного университета им.П.Г.Демидова- 2012- №2, с.128-133

3. Погорелова Е.И., Барбурова Е.Е. Жизнестойкость семейных пар и удовлетворенность браком// Психология стресса и совладающего поведения. Ресурсы, здоровье, развитие. Материалы IV Международной научной конференции: в 2-х томах. /Отв. редакторы: Т.Л. Крюкова, М.В. Сапоровская, С.А.Хазова. - Кострома, 2016, с.87-89

\section{ЭФФЕКТИВНОСТЬ АКТИВНОСТИ СОВРЕМЕННЫХ РОССИЙСКИХ ПОКОЛЕНИЙ}

Пищик В.И.

В настоящее время мы живем в изменяющемся мире, в мире «текучей реальности». Критерии оценки деятельности человека эфемерны и неустойчивы, поскольку подвижны и изменчивы критерии и границы реальности. В этой связи становится актуальной проблема оценки эффективности деятельности персонала. Но мы бы хотели перейти к оценке эффективности не вообще персонала, а его представителей, относящихся к различным группам поколений. Выделяют поколение, победившее во второй мировой войне, «потерянное» поколение или творческое поколение 60-гг., поколение застоя, поколение «пепси». В обществе существует различное отношение к типам поколений. Оно оценивается как более эффективное или менее. Сегодня мир кординально изменился. Очень много свобод и возможностей. Человек должен знать, что ему делать со своей свободой. Современным типом неопределенности является не отсутствие средств, а отсутствие и поиск целей [4]. Поскольку обществом не управляет традиция, то количество возможностей растет. Не хватает правил, паттернов и кодексов, которые определили бы ориентиры движения [1, с. 13]. Эпоха референтных групп закончилась, наступила эпоха тотального сравнения со всеми. При постоянно растущих возможностях потребности человека удовлетворяются, но не на долго. Сегодня усилия, прилагаемые к достижению цели, изменяются со временем и возникнет неопределенность. В этой связи представляется, что размыты критерии эффективности и как бы мы их искусственно не создавали, они изменятся через какое-то время и придется создавать новые критерии. Критериев великое множество и они часто противоречат друг другу.

Одним из критериев эффективности социальных форм сегодня является скорость и мобильность, умение меняться, которые являются основой власти и доминирования в современном обществе. Субъективно время жизни сжимается, плотность времени растет. Благодаря Интернету изменилось отношение к 